\title{
Spatial language facilitates spatial cognition: Evidence from children who lack language input
}

\author{
Dedre Gentner $^{\mathrm{a}, *}$, Asli Özyürek ${ }^{\mathrm{b}, \mathrm{e}}$, Özge Gürcanli ${ }^{\mathrm{c}}$, Susan Goldin-Meadow ${ }^{\mathrm{d}}$ \\ ${ }^{a}$ Northwestern University, United States \\ ${ }^{\mathrm{b}}$ Radboud University Nijmegen, The Netherlands \\ ${ }^{\mathrm{c}}$ Rice University, United States \\ ${ }^{\mathrm{d}}$ University of Chicago, United States \\ ${ }^{\mathrm{e}}$ Max Planck Institute for Psycholinguistics, The Netherlands
}

\section{A R T I C L E I N F O}

\section{Article history:}

Received 5 January 2011

Revised 19 December 2012

Accepted 11 January 2013

\section{Keywords:}

Language and thought

Spatial cognition

Spatial language

Deaf vs. hearing

Homesign

\begin{abstract}
A B S T R A C T
Does spatial language influence how people think about space? To address this question, we observed children who did not know a conventional language, and tested their performance on nonlinguistic spatial tasks. We studied deaf children living in Istanbul whose hearing losses prevented them from acquiring speech and whose hearing parents had not exposed them to sign. Lacking a conventional language, the children used gestures, called homesigns, to communicate. In Study 1, we asked whether homesigners used gesture to convey spatial relations, and found that they did not. In Study 2, we tested a new group of homesigners on a Spatial Mapping Task, and found that they performed significantly worse than hearing Turkish children who were matched to the deaf children on another cognitive task. The absence of spatial language thus went hand-in-hand with poor performance on the nonlinguistic spatial task, pointing to the importance of spatial language in thinking about space.
\end{abstract}

(c) 2013 Elsevier B.V. All rights reserved.

\section{Introduction}

Learning to represent and reason about space is crucial to children's cognitive development. A body of recent evidence suggests that human representations of space and its development are influenced by the way in which space is codified in the language people learn (Bowerman, 1996; Haun, Rapold, Call, Janzen, \& Levinson, 2006; Hermer-Vasquez, Spelke, \& Katsnelson, 1999; Levinson, 2003; Loewenstein \& Gentner, 2005; Majid, Bowerman, Kita, Haun, \& Levinson, 2004). However, this research remains controversial (Li \& Gleitman, 2002; for reviews, see Gentner \& Goldin-Meadow, 2003; Gleitman \& Papafragou, 2005; Gumperz \& Levinson, 1996; Malt \& Wolff, 2010). Here we

\footnotetext{
* Corresponding author. Address: Northwestern University, Department of Psychology, 2029 Sheridan Rd., Chicago, IL 60208, United States. Tel.: +1 847467 1272; fax: +1 8474917859 .

E-mail address: gentner@northwestern.edu (D. Gentner).
}

address this issue in a novel way by investigating nonlinguistic spatial skills in deaf children who have not been exposed to a conventional language, and comparing their skills to those of cognitively-matched hearing children who have learned a conventional language.

Much of the evidence for effects of spatial language on spatial cognition comes from developmental research suggesting that learning spatial language invites children to form corresponding conceptual representations of space. This work is consistent with the "cognitive tool kit" view-that language provides symbolic systems that potentiate new ways to represent and reason about the world. On this account, language augments, but does not replace, other kinds of representations, such as modalityspecific representations (Frank, Everett, Fedorenko, \& Gibson, 2008; Gentner, 2003, 2010; Gentner \& Christie, 2010).

If the language we speak provides us with cognitive tools, then it should be possible to observe this influence as children acquire their language. There is, in fact, evi- 
dence that learning spatial language can influence children's spatial cognition. Pruden, Levine, and Huttenlocher (2011) found that children's production of spatial terms from 14 to 46 months predicted their performance on nonlinguistic spatial tasks at 54 months. There is also evidence that acquiring particular spatial words can influence children's spatial skills. For example, preschool children who have acquired the words left/right are better able to use a landmark to re-find a hidden object than children who have not acquired the words (Hermer-Vasquez, Moffet, \& Munkholm, 2001). Likewise, preschool children who have acquired the term middle perform better on a midpoint search task than those who have not (Simms \& Gentner, 2008).

There is, in addition, evidence for a second prediction that follows from the tool-kit view--that early in development, before the relevant terms are entrenched, reminding children of particular spatial terms can improve their spatial performance. For example, preschool children are better able to retain color-location conjunctions in a shortterm memory task if the words left and right are used during the task (Dessalegn \& Landau, 2008). In research directly relevant to the present study, Loewenstein and Gentner (2005) found that children perform better on a challenging Spatial Mapping Task when spatial termseither top, middle, bottom or on, in, under-are used in the task than when they are not.

Although these findings are consistent with the prediction that spatial cognition benefits from the acquisition of spatial language, in many cases they are open to other interpretations. For example, the benefits accrued from using spatial language at task time could potentially be explained as temporary priming effects; and the correlations found between children's command of spatial language and their nonlinguistic spatial competence might simply reflect some third factor-such as a maturational or experiential advantage-that influences both.

Another approach to the question is to examine spatial cognition in individuals who vary in the spatial language available to them. Pyers, Shusterman, Senghas, Spelke, and Emmorey (2010) tested two cohorts of deaf signers in Nicaragua--one who acquired Nicaraguan Sign Language (NSL) when the language was in its initial stage of development (1st cohort), and another who acquired NSL 10 years later after the language had evolved a richer vocabulary and more complex constructions (2nd cohort). They found that the 2 nd cohort did, in fact, use more consistent spatial language than the 1 st cohort, and also performed significantly better on two nonlinguistic spatial navigational tasks (finding a location after being disoriented and after an array had been rotated) than the 1 st cohort. Moreover, the use of specific spatial terms was related to performance on particular spatial tasks: consistent marking of left-right relations correlated with performance on the self-disorientation task, and marking information about the grounded object correlated with performance on the array-rotation task. These patterns suggest a strong relation between spatial language and spatial cognition.

Pyers et al. (2010) studied adults who have access to a conventional language, albeit not a completely devel- oped one (see Senghas \& Coppola, 2001; Senghas, Kita, \& Özyürek, 2004); the adults might thus have relied on language when performing the nonlinguistic spatial tasks even though it is not essential to do so. The findings thus leave open the possibility that individuals who have not had any exposure to conventional language might still be able to solve the spatial cognition tasks using an approach that does not rely at all on language. To explore this possibility, Hyde et al. (2011) studied a deaf child who had grown up in an underdeveloped country and had not been exposed to sign language, knew no spoken language, and had received no formal schooling or therapeutic intervention during childhood. At the age of 13, he immigrated to the United States and came to the attention of the researchers. The child was able to convey the number of objects displayed in a scene using gesture. However, he was not able to describe the spatial relationship between two objects (e.g., that a cat was on top of a dog) in gesture. Interestingly, the child was also unable to perform a navigational task following disorientation. These findings make two points. First, conveying spatial relations in gesture is not as easy as it seems. Second, having a representational system for conveying spatial relations seems to facilitate and may even be essential to performing certain spatial tasks.

Our study extends and deepens these findings. Whereas the Hyde et al. (2011) study focused on a single child whose early history was essentially unknown, our study examined five deaf children living in Istanbul, Turkey, whose circumstances were well documented. All of the children had hearing losses that prevented them from learning a spoken language, and their hearing parents had not exposed them to a conventional sign language, either because there were no sign programs available or because the parents did not want their children to learn sign language. We explored the impact of this lack of a language model on a more abstract spatial task than was explored in either the Pyers et al. (2010) or Hyde et al. (2011) studies--the ability to map spatial relationships from one spatial array to another (Loewenstein \& Gentner, 2005).

We examined this spatial skill in deaf children lacking exposure to Turkish Sign Language. The deaf children were well integrated into their hearing families but because they had no access to a conventional language model, they used gestures, called homesign, to communicate. Homesigns have been found to display many properties of natural language (Goldin-Meadow, 2003) but, aside from the Hyde et al. (2011) study, there have been no systematic investigations of whether homesigners convey spatial relations. In addition, to provide a cultural baseline, we examined the same skill in hearing children from the same socio-economic and cultural milieu in Istanbul who were acquiring Turkish.

The specific hypothesis we test is that learning and routinely using spatial language makes it relatively easy for children to access the relational system that underlies the linguistic encoding--easier than it would be if the children had not been exposed to and learned spatial language. We thus ask two questions: (i) Do homesigners invent gestures that portray spatial relations (Study 1)? 
(ii) Do homesigners perform as well on a nonlinguistic Spatial Mapping Task as children who have learned conventional terms for spatial relations (Study 2)? If language is instrumental in developing fine-tuned spatial representations, and if the gesture systems of deaf homesigners lack linguistic encoding of spatial relations, then homesigners ought to perform poorly on tasks that require such representations.

To accomplish these goals, we gave Turkish homesigners and Turkish hearing children a Language Elicitation Task in Study 1 and a Spatial Mapping Task in Study 2. In the Language Elicitation Task, we focused particularly on spatial relations relevant to the Spatial Mapping Task-on, in and under and top, middle and bottom. To preview the results of Study 1, we find that, by age 4, Turkish hearing children have acquired the relevant spatial terms; however, Turkish homesigners have not developed gestural techniques for conveying the spatial relations relevant to the mapping task even at age 5. In Study 2, we then test Turkish homesigners and hearing children, matched for cognitive level on the basis of a Mental Transformation Task (see Section 4), on the Spatial Mapping Task.

\section{Study 1: Spatial Language Elicitation Task}

Our goal in Study 1 was to determine whether Turkish homesigners convey spatial relations relevant to the Spatial Mapping Task in their gesture systems. However, before turning to the homesigners, we need to be certain that young Turkish hearing children have devices for these particular spatial relations in their linguistic repertoires. In all languages, locative expressions encode the relation between one entity (figure) and another (ground). The ground is the bigger, more stable and/or backgrounded entity; the figure is the smaller or more mobile entity and the focus of attention. Two basic relations between figure and ground are typically encoded in languages (Talmy, 1975, 1983): (1) directional relations, in which the figure moves with respect to the ground (man walks to car); (2) spatial relations in which the figure is located with respect to the ground (bird is on tree). It is this second type of relation that we hypothesize will be most beneficial to succeeding on the Spatial Mapping Task.

To convey directional relations, Turkish uses case markers, suffixes that are attached to nouns. For example, the ablative marker -dan in example (1), which is attached to the noun masa (table), conveys the source (i.e., from the table); the dative marker $-a$ in (2), which is attached to the noun araba (car), conveys the goal (i.e., to the car).

$\begin{array}{lll}\text { (1) Fincan } & \text { masa-dan } & \text { düştü } \\ \text { cup } & \text { table- } & \text { fell } \\ & \text { CASE:ABL } & \end{array}$

The cup fell from the table

(2) Çocuk child

The child went to the car
To convey spatial relations, Turkish uses postpositions. Postpositions are comparable to English prepositions in that they are independent, closed class words that convey the spatial relation between entities; however, unlike prepositions, which come before nouns (e.g., on the table), postpositions come after nouns. Postpositions in Turkish are always accompanied by case markers. In example (3), a static spatial relation between the cup and the table is conveyed with a postposition (üst) followed by a spatial case marker (-de = LOC). Examples (4) and (5) each describes a dynamic relation; the spatial relation between the entities is again conveyed by a postposition (üst, iç) and the dynamic information is conveyed by a directional case marker $(-d e n=\mathrm{ABL}$, $-e=\mathrm{DAT})$. In these examples, the postposition üst is roughly comparable to English on/top, and iç is comparable to English in. LOC refers to the locative case (comparable to English at), ABL refers to Ablative case (comparable to English from), and DAT refers to the Dative case (comparable to English to). The other case markers, POSS (possessive) and GEN (genitive), are obligatory and indicate a possession relation between two entities (possession here includes inalienable possession, as in the top of the table).

$\begin{array}{lll}\text { (3) Fincan } & \text { masa- } & \text { üst-ün-de } \\ & \text { nin } & \\ \text { cup } & \text { table- } & \text { on/top/over-GEN- } \\ & \text { POSS } & \text { CASE:LOC }\end{array}$

The cup is on the table

$\begin{array}{llll}\text { (4) Fincan } & \text { masa- } & \text { üst-ün-den } & \text { düştü } \\ & \text { nın } & & \\ \text { cup } & \text { table- } & \text { on/top/over-GEN- } & \text { fell } \\ & \text { POSS } & \text { CASE:ABL } & \end{array}$

The cup fell from the top of the table

$\begin{array}{llll}\text { (5) Çocuk } & \text { araba- } & \text { iç-in-e girdi } & \\ & \text { nın } & & \\ \text { child } & \begin{array}{l}\text { car- } \\ \end{array} & \text { in-GEN-CASE:DAT } & \text { enter- } \\ & & \text { PAST-3rd }\end{array}$

The child went/entered into the car

To determine whether young Turkish hearing children have devices in their linguistic repertoires that encode the spatial relations relevant to the nonlinguistic mapping task used in Study 2, we searched the Aksu corpus in the Child Language Data Exchange System (CHILDES, MacWhinney, 2000) for all instances of the following four postpositions: üst (on/top), alt (under/bottom), orta (middle), and ara (between). ${ }^{1}$ This corpus contains spontaneous utterances and guided conversations produced by 34 Turkish hearing children ranging in age from $2 ; 0$ to $4 ; 8$ (years;months). The data were collected between 1972 and 1973 at intervals of 4 months; each visit took place either in the child's home or at preschool. Tagging according to part of speech was done by the third author (OG), a native speaker of Turkish. We found that üst (top/on) was produced by 22 children

\footnotetext{
1 Turkish does not have distinct linguistic devices corresponding to English on vs. top and instead uses the same postposition for both meanings; the same is true for bottom vs. under (see example 4).
} 
(82 instances), alt (under/bottom) by 20 children (34 instances), orta (middle) by five children (nine instances), and ara (between) by three children (10 instances). The first instances of üst and alt appeared at 2;0; orta at 2;8, and ara at $3 ; 4$.

We also searched the corpus for all instances of three case markers conveying directional relations: $a$ (to), dan (from), and $d a(a t)$. We found that all three case markers were produced by the 34 Turkish children at age 2;0, and were frequent at each age. Since it is common in adult Turkish to use a case marker without a postposition (but the converse is not the case, i.e., a postposition is never produced without a case marker), it is not surprising that case markers conveying directional relations are more common in Turkish hearing children than postpositions conveying spatial relations. Nevertheless, the important point is that all 34 Turkish children in the CHILDES corpus had some control over linguistic devices relevant to the Spatial Mapping Task in Study 2.

We are now ready to ask whether Turkish homesigners produce gestures conveying these same spatial relations. To address this question, we presented 5 Turkish homesigners (and 10 Turkish hearing children serving as controls) with short videos of events that that have been shown to elicit spatial language in previous studies (Goldin-Meadow, So, Özyürek, \& Mylander, 2008). We focused on the children's responses to a set of vignettes likely to elicit descriptions of the spatial relations relevant to the Spatial Mapping Task in Study 2 (e.g., a vignette displaying a man carrying a chicken and placing it on a scaffold).

\subsection{Method}

\subsubsection{Participants and procedure}

Five Turkish deaf homesigners (mean age $4 ; 8$, or 56 months; range $=46-66$ months, $S D=8.07$ ), and 10 Turkish hearing children (mean age $3 ; 10$, or 46 months; range $=38-58$ months, $S D=8.6$ ) living in Istanbul participated in the study. The deaf children had congenital bilateral hearing losses (70-90 dB) that prevented them from acquiring spoken Turkish. In addition, their hearing parents had decided to educate them using oral methods and had not exposed them to Turkish Sign Language. As a result, the deaf children had no conventional language model to guide them and used homesign to communicate.

Children were tested individually in their homes and shown 48 short video clips as part of a larger study. After each clip, the children were asked to describe to the experimenter what happened. For deaf children, the experimenter produced a questioning gesture (hand rotates from palm down to palm up) to which children responded by gesturing about the event. To facilitate memory and communication, we provided a picture of the characters in the event to which the children could refer. We selected the five vignettes most likely to elicit the spatial relations relevant to the Spatial Mapping Task used in Study 2 (i.e., on/top, in): man moves to sit on motorcycle; man carries chicken and places it on scaffolding; duck moves and lands in a wheelbarrow; tool box moves on top of a school bus; train moves and stops in a fenced area.

\subsubsection{Coding}

We coded all the speech that the hearing children produced and all the gestures that the deaf children produced when describing the vignettes.

2.1.2.1. Speech coding. For the hearing children, we classified an utterance as a sentence if it included at least two words-either an action predicate with one (or more) argument(s), or two arguments conjoined by an existential predicate (e.g., "is"), which can be omitted in Turkish. We classified a sentence as encoding a directional relation if it included a directional case marker attached to a noun referring to the ground (e.g., DAT in example (6)). We classified a sentence as encoding a spatial relation if it not only included a directional case marker (e.g., DAT in example (7)), but the case marker was also attached to a postposition (e.g., üst = top of in example (7)). Any Turkish sentence that contains a postposition (and thus conveys a spatial relation) must also contain a case marker; the stimuli in our study all displayed dynamic relations, and thus when they elicited case markers, those case markers were directional (i.e., DAT or ABL as opposed to LOC; see examples (4) and (5), compared to (3)).

\begin{tabular}{lll}
\hline (6) & $\begin{array}{l}\text { Bura-y-a } \\
\text { Here-CASE:DAT }\end{array}$ & \multicolumn{1}{c}{ geldi } \\
came & & \\
(This one) came (to) here & geldi \\
(7) & $\begin{array}{l}\text { Kamyonun } \\
\text { truck-POSS }\end{array}$ & top-GEN-CASE:DAT \\
(Box) came to the top of the truck & \\
\hline
\end{tabular}

2.1.2.2. Gesture coding. We transcribed all of the gestures that the deaf children produced when describing the vignettes. The children used pointing gestures, which referred to entities (here, the figure and ground), and iconic (depictive) gestures, which referred to the actions portrayed in the vignette. Gestures were divided into sentences using motoric criteria (see Goldin-Meadow \& Mylander, 1984): A pause or relaxation of the hands signaled the end of a sentence. We focused on sentences containing at least two gestures (combinations of pointing gestures, combinations of iconic gestures, or combinations of pointing and iconic gestures).

Our coding of the homesigners' gestures was guided in part by the devices used in sign languages to convey spatial relations. ${ }^{2}$ Conventional sign languages typically have two ways of referring to spatial relations-both involving two hands. One way is to use prepositions or postpositions (socalled "relational lexemes" in sign languages, Arik \& Wilbur, 2008)-two-handed signs that convey a generic spatial relation between figure and ground such as ON and IN. It is important to note that spatial lexemes of this sort are relatively rare in conventional sign languages and, even if the terms exist in a particular sign language, signers use them

\footnotetext{
2 Emerging signed languages, such as Al-Sayyid Bedouin Sign Language (Meir, Sandler, Padden, \& Aronoff, 2010), would potentially be a useful source of guidelines here, but we were unable to find any published discussions of how (or whether) spatial relations are represented in such languages.
} 


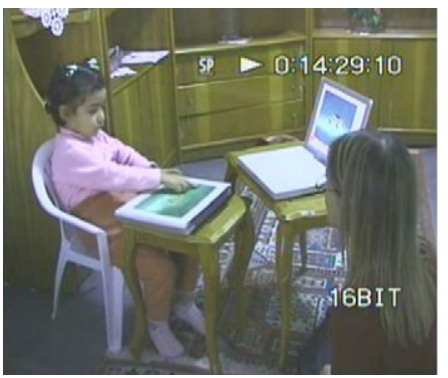

$\mathrm{RH}$ : point to box $(\mathrm{F})$ FIGURE

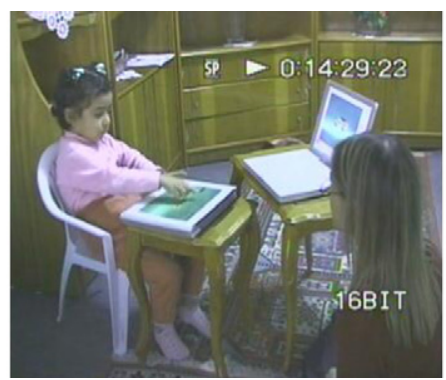

RH: move from box $(\mathrm{F})$ to bus $(\mathrm{G})$ ACTION

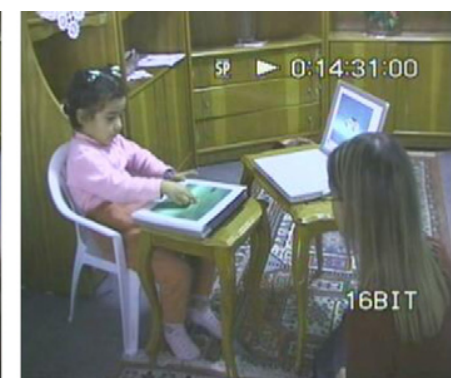

RH: point to bus $(\mathrm{G})$ GROUND

Fig. 1. An example of a directional relation produced by a Turkish homesigner describing a box which moves on top of a bus ( $\mathrm{F}=$ figure; $\mathrm{G}=$ ground).

infrequently to convey spatial relations (Emmorey, 2002a; Özyürek, Zwitserlood, \& Perniss, 2010). The second, preferred, way to convey spatial relations is to use complex classifier predicates. In these predicates, one hand represents the figure and the other the ground, and the simultaneously produced positions and movements of the hands encode the relation between the two (Emmorey, 1996, 2002b; Engberg-Pedersen, 1993; Perniss, Vermeerbergen, Leeson, \& Crasborn, 2007; Supalla, 1982, 2003). In a classifier predicate construction, the hand representing the ground is typically first located in space, and the hand representing the figure is then placed in relation to the hand representing the ground. We thus coded the homesigners' gestures in terms of the semantic element represented by the hand (figure, ground), the placement of the hands in relation to one another, and the order in which the hands were produced and located.

We looked for gestures that might be serving a preposition-like function (e.g., a generic representation of in or on) and, perhaps not surprisingly given the paucity of such terms in established sign languages (Emmorey, 2002a; Özyürek et al., 2010), found none. The homesigners did, however, produce some sentences containing gestures for the figure and the ground. We examined these sentences to determine whether they could be construed as conveying either directional or spatial relations.

2.1.2.2.1. Directional relations. The deaf children produced gesture sentences conveying figures and grounds in relation to a moving action; these sentences seemed to capture the "to" and "from" meanings conveyed in Turkish and thus conveyed a directional relation. For example, one child produced a pointing gesture at the figure, followed by an iconic gesture for the moving act, and finally by a pointing gesture at the ground (see Fig. 1). We classified all sentences containing an act gesture combined with gestures for the figure and ground as conveying a directional relation, independent of order (i.e., figure-act-ground; groundfigure act; act-figure-ground, etc.). We also included in this category two-gesture sentences in which a gesture for the act was combined with a pointing gesture for the figure (figure-act; act-figure) or the ground (ground-act; actground) since these sentences also convey movement from the figure or to the ground.
2.1.2.2.2. Spatial relations. Sentences conveying directional relations situate the figure and/or ground in relation to the action (from the figure, to the ground) but they do not convey the specific relation between figure and ground. To do so, the sentence must contain a gesture for the figure situated in relation to the ground. As noted earlier in this section, conventional sign languages typically convey spatial relations by producing a sign for the ground in space and then producing a sign for the figure in relation to that space; the two signs can either be produced simultaneously (which results in a two-handed sign) or sequentially. This pattern has been found in all established sign languages studied to date: ASL (Emmorey, 1996, 2002b; Supalla, 2003), British Sign Language (Morgan \& Woll, 2007), Danish Sign Language (Engberg-Pedersen, 1993), German Sign Language (Perniss et al., 2007), Quebec Sign Language (Miller, 1994), Hong Kong Sign Language (Tang, Sze, \& Lam, 2007).

The deaf children in our study did not produce iconic gestures for figures and grounds but rather pointed at the figure or ground in the pictures of the scenes we provided as a memory aid. As a result, the children did not produce gestures for figure or ground in space and thus produced no instances of the type of ground-figure constructions found in established sign languages. However, the children did, at times, produce a point at the place on the picture where the figure ended up after the movement (i.e., a point conveying the figure's final location), as well as a point at the ground on the picture; the point at the ground could be produced before or after the point at the figure, or simultaneously with the point at the figure (see Fig. 2). Gesture sentences of this type specified the relation between figure and ground, and thus were classified as conveying a spatial relation.

\subsection{Results}

To determine whether deaf and hearing children used their gestures and speech, respectively, in similar ways in the spatial elicitation task, we examined the number of sentences that the children produced per event. We found that the deaf children produced, on average, 2.16 $(S D=1.32)$ gesture sentences per event, which did not differ significantly from the $2.62(S D=1.76)$ spoken sentences 


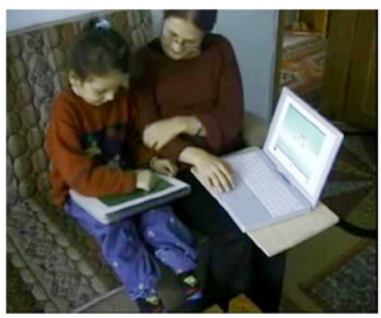

RH: point to box $(F)$ FIGURE

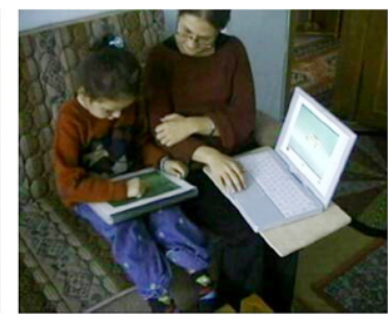

RH: move from box (F) to bus $(\mathrm{G})$ ACTION

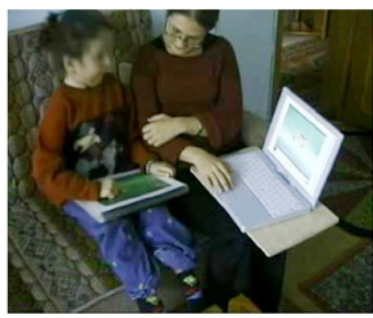

RH: point to bus $(\mathrm{G})$ GROUND

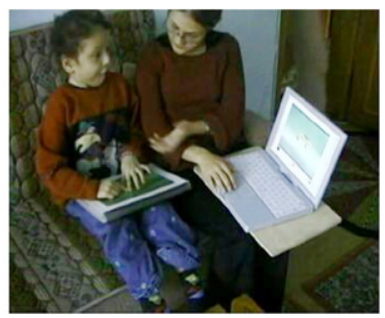

RH: point to bus $(\mathrm{G})$

LH: point to place on bus where the box landed (i.e., F's final location) RESULTING SPATIAL RELATION

Fig. 2. An example of a spatial relation produced by a Turkish homesigner describing a box which moves on top of a bus ( $F=$ figure; $G=$ ground $)$.

that the hearing children produced per event, $u=30.5$, $p=.513$, two-tailed, Mann-Whitney $U$ test. The mean number of gestures that the deaf children produced per string was $2.6(S D=0.23)$, compared to $2.9(S D=0.46)$ words per string for the hearing children, $u=35.0, p=.25$, two-tailed, Mann-Whitney $U$ test.

We next examined the proportion of sentences conveying directional or spatial relations that the children produced. Fig. 3 presents the data. Both deaf and hearing children produced a sizable proportion of sentences conveying directional relations: .65 $(S D=.22)$ for the deaf children and $.59(S D=.22$ for the hearing children-a nonsignificant difference, $u=.30$, $n s$, two-tailed, MannWhitney $U$ test. Importantly, however, the deaf children produced a significantly smaller proportion of sentences conveying spatial relations than the hearing children, .03 $(S D=.04)$ for the deaf children vs. $.28(S D=.18)$ for the hearing, $u=45.0, p=.013$, two-tailed, Mann-Whitney $U$ test. Note that because Turkish requires that a directional case marker be produced along with a spatial postposition in constructions that convey spatial relations (see example 7 ), whenever the hearing children conveyed the spatial relation between figure and ground in a sentence, that sentence also conveyed a directional relation. In other words, both deaf and hearing children conveyed directional information, but only the hearing children also conveyed the resulting configuration of figure and ground. ${ }^{3}$

Looking more closely at the types of gesture sentences conveying directional relations that the deaf children produced, we found that the deaf children frequently combined gestures for the figure and the act (figure-act, $n=9$; act-figure, $n=0$ ) and gestures for the ground and the act (ground-act, $n=4$; act-ground, $n=8$ ). They also produced a relatively small number of sentences containing gestures for all three semantic elements (figure-act-ground, $n=4$; figure-ground-act, $n=2$; ground-figure-act, $n=4$; ground-

\footnotetext{
3 The Turkish homesigners' failure to include gestures for specific static spatial relations parallels previous findings by Goldin-Meadow and Mylander (1984). In a study of the action and semantic relations that six American homesigners encoded in their gestures, they found that all six children gestured about static spatial location, but did so by producing two pointing gestures, one for the figure and one for the ground. Importantly, they did not produce gestures describing the relation between figure and ground.
}

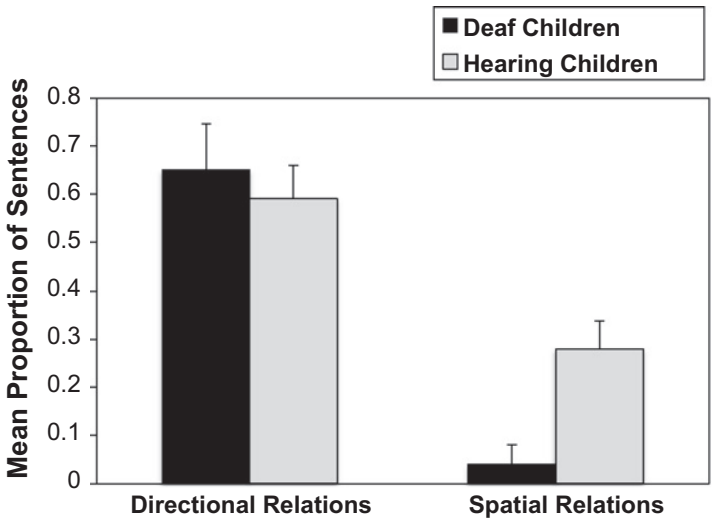

Fig. 3. The mean proportion of sentences that the deaf (gray bars) and hearing (black bars) children produced in the Language Elicitation Task conveying directional or spatial relations.

act-figure, $n=1$; act-figure-ground, $n=0$; act-ground-figure, $n=1$ ). All five children produced gesture sentences conveying directional relations.

In contrast, the deaf produced only two instances of gesture sentences conveying spatial relations, one in which a gesture for the final location of the figure was produced after the point at the ground (which was kept in place), and one in which a gesture for the final location of the figure what was produced simultaneously with the gesture for the ground (see Fig. 2). The homesigners thus use their gestures essentially to convey directional relations, but not to convey spatial relations (i.e., the position of the figure in relation to the ground $)^{4}$

\footnotetext{
${ }^{4}$ We also examined the co-speech gestures that 7 of the hearing children produced along with their descriptions of the events, and found that they produced fewer gesture sentences per event than the deaf children (.64, $\mathrm{SD}=.46$ hearing vs. $2.16, \mathrm{SD}=1.32$, deaf). Looking then at proportion of gesture sentences, we found that the hearing children produced .60 $(\mathrm{SD}=.23)$ gesture sentences that fit our criteria for conveying directional relations (compared to $.65, \mathrm{SD}=.22$, for the deaf children), and no gesture sentences conveying spatial relations (compared to .03 , $\mathrm{SD}=.04$, for the deaf children). The hearing children produced as many ground + action gesture combinations as the deaf children (11 vs. 12) but fewer figure + action ( 0 vs. 9 ) and figure + action + ground ( 2 vs. 12 ) combinations than the deaf children. The relatively small number of figure gestures that the Turkish hearing children produced may reflect the fact that the figure is often dropped in spoken Turkish (see example 7 in text).
} 
Overall, we found no evidence that homesigners invent gestures or constructions that they routinely use to portray spatial relations. This result paves the way for our second question--does the lack of symbols or constructions for spatial relations affect children's performance on a nonlinguistic spatial task? If language is instrumental in developing fine-tuned spatial representations, then children who lack spatial language should perform poorly on tasks that require such representations. To test this prediction, we gave two new groups ${ }^{5}$ of deaf and hearing children the Loewenstein and Gentner (2005) Spatial Mapping Task.

\section{Study 2: Nonlinguistic Spatial Mapping Task}

We tested new groups of Turkish homesigners and Turkish hearing children (matched on a separate cognitive task) on Loewenstein and Gentner's (2005) Spatial Mapping Task, on which English-speaking children have been found to display effects of spatial language. In this task, children are presented with two identical three-tiered boxes (see Fig. 4, top), each containing three cards. One card (the "winner") has a star on its back. The experimenter shows the child the location of the winner in the hiding box and asks the child to point at the winner in the finding box. The winner is always in the same spatial location in the two boxes (i.e., top, middle, or bottom in both boxes). Preschool children find this task challenging. Importantly, their performance can be dramatically improved if the experimenter uses spatial relational words during the task, saying, for example, "I'm putting it at the top (middle, bottom) of the box" while placing the winner in the hiding box, as opposed to saying "Look, I'm putting it here" (Loewenstein \& Gentner, 2005). Loewenstein and Gentner concluded that providing spatial relational language invited children to form a delineated representation of the spatial structure, and that this precise encoding helped them to carry out an accurate spatial mapping.

To rule out alternative explanations (e.g., that language simply focuses children's attention during the task), Loewenstein and Gentner (2005) brought the children back to the lab a few days later and asked them to "play the same game" with no mention of the spatial terms. Children who had previously heard spatial language continued to perform significantly better than children who had notsuggesting that the use of spatial language invited specific spatial encodings, which were then retained over time. Another indication that spatial language acts to invite a specific spatial encoding comes from a study in which a new group of 3-year-olds was asked simply to remember the location of a hidden toy in one of the three-tiered boxes. They were significantly better able to do so if the box had been labeled with on, in, and under before the task (Loewenstein \& Gentner, 2005, unpublished). Finally, Loewenstein and Gentner (2005) found the same advantage in studies in which the spatial terms were used before

\footnotetext{
5 Studies 1 and 2 were run at different times. We therefore needed a largely new group of homesigners to maintain the desired age range. Because of the uniform lack of spatial language among the homesigners in Study 1 , we felt reasonably confident that this new group would also lack spatial language.
}

the task and not during the task (e.g., "We're going to play the top, middle, bottom game").

Loewenstein and Gentner (2005) also found that older children ( $51 / 2-7$ years) performed well even when not provided with overt spatial language, suggesting that with repeated usage the spatial representations invited by a language can become habitual encodings. These results led us to ask whether homesigners, who lack linguistically encoded spatial relations, would be disadvantaged on this task relative to children who have acquired spatial language. ${ }^{6}$

To address this question, we administered the Spatial Mapping Task to homesigners and to hearing children from the same middle-class socio-economic milieu in Istanbul. In order to ensure that the homesigners and hearing children were matched for general cognitive and perceptual abilities, we administered a test of basic spatial skillsthe Mental Transformation Task (MTT) developed by Levine, Huttenlocher, Taylor, and Langrock (1999). To avoid carryover, this task was run after the Spatial Mapping Task for all children. Because we had a limited population of 13 homesigners, we initially tested a larger group of 23 hearing children on the Spatial Mapping Task. We then gave all the children the MTT, and retained only the 13 hearing children whose scores on the MTT most closely matched those of the deaf children. We describe the tasks in the order in which they were conducted: the Familiarization task and the Spatial Mapping Task in Section 3, and the Mental Transformation Task in Section 4.

\subsection{Method}

\subsubsection{Participants}

The participants were 13 homesigners and 13 hearing children, all from middle-class families living in Istanbul, matched on the Mental Transformation Task, as described earlier. The mean age of the 13 deaf children was 5 years; 6 months or 66.5 months, with a range of $50-78$ months $(S D=9.45)$. The mean age of the 13 hearing children was $4 ; 10$ or 58.7 months, with a range of $49-77$ months $(S D=7.87)$. Two of the 13 deaf children also participated in the Language Elicitation Task (Study 1).

3.1.1.1. Procedure for familiarization. To be certain that the deaf children understood the task, we began with a familiarization session of roughly 10-15 min (hearing children received a briefer warm-up session of about 2-3 min). Our goal in the familiarization session was to ensure that the deaf children understood and could use the gestures that would be used during the study. Many were conventional gestures used by Turkish speakers and were already known to the children; for example, head-nodding for affirmation; head shaking for negation; a beckoning gesture for "give me;" left and right index fingers held side by side for "same;" and turning one or both hands over (from palm-down to palm-up) for questioning. We went

\footnotetext{
${ }^{6}$ As noted earlier, Turkish makes a distinction between top, middle and bottom in highly frequent spatial constructions; we therefore expect Turkish-speaking children to have the same advantages on this task as English-speaking children.
} 
Neutral

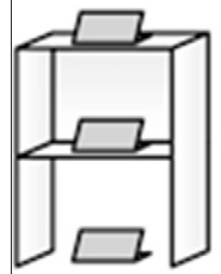

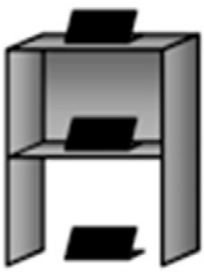

Relational Match
Cross-Mapped
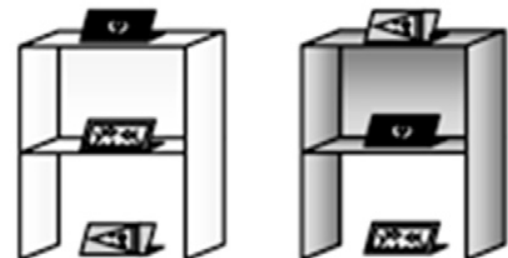

Relational Match with Competing Object Match

Performance on Neutral and Cross-Mapped Spatial Mapping Tasks by Deaf and Hearing Children

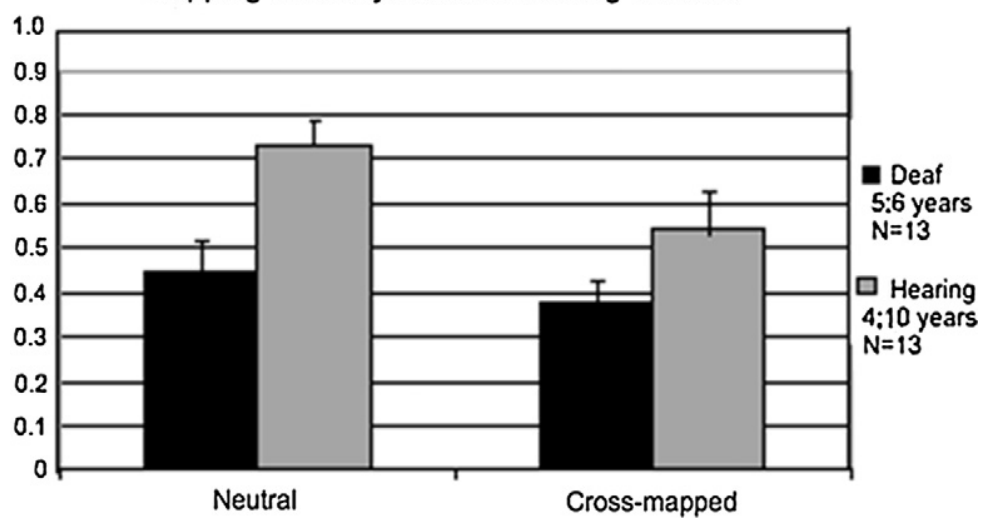

Fig. 4. Examples of the shapes and choice cards shown to the deaf and hearing children in the Mental Transformation Task.

through each of these gestures with the children to be certain that they understood them and to put them at ease.

Because the terms same and different are important to the study, we spent additional time illustrating gestures for the terms. The experimenter introduced five pairs of identical objects (e.g., two pencils, two small balls, etc.). For same, the experimenter pointed back and forth repeatedly between the two identical pencils, and then made the "same" gesture (described in the preceding paragraph) while nodding her head. For different, she pointed back and forth between a pencil and a cup (for example), and then shook an upright index finger in the air over the objects while shaking her head. Same and different were each illustrated with multiple pairs until the child showed accurate comprehension of the gestures by producing an object that was the same as (or different from) a target object for three consecutive target objects. Two additional gestures were introduced during the study: a "winner" gesture, as described in the next section, and a "close your eyes" gesture, in which the experimenter gestured holding hands over her eyes. Children readily learned these gestures (or already knew them from children's games) and produced them over the course of the study.

3.1.1.2. Practice trials. Two three-tiered boxes, one white (the hiding box) and the other blue (the finding box), were placed about three feet apart on the carpet (Fig. 4, top).
Each box contained three cards, identical except for color--white in the hiding box, blue in the finding box. Two additional cards (one of each color) were used in the practice trials (and in the check trials; see next section), resulting in a total of four cards per box for these trials. For each box, one of the cards had a star on its back and was called the "winner" card (designated verbally for the hearing children and with an arm-pumping "champion" or "victory" gesture for the deaf children-a gesture they immediately understood and copied). Children were shown and told (in speech for the hearing children, in gesture for the deaf children) that the winner card was in the same place in the hiding and finding boxes.

Children were then given easy practice trials to ensure that they understood the task. On these trials, the two boxes each contained three cards, one in each tier (as always throughout the task). For the practice trials, we used a fourth card in each box. In these trials, the two winner cards were each placed on the floor next to their box, in corresponding locations (i.e., both left or both right of their box). On the first practice trial, the experimenter showed the child that she was placing one winner card to the right of the hiding box. Then she showed the child that she was placing the other winner to the right of the finding box. The children's task was simply to point to the winner card beside the finding box. Not surprisingly, all children were successful on this task. The experimenter then highlighted 
in speech or gesture the correspondence between the locations of the two winner cards. On the next practice trial, the children watched the experimenter place a winner card to the left of the hiding box. The children then closed their eyes while the experimenter placed the second winner card in the corresponding location-that is, to the left of the finding box. The children then had to point to the winner card at the finding box-again, an easy task, as the two winner cards in their corresponding locations were the only cards outside of the boxes. If children did not perform correctly on this practice trial, they were given extra practice trials; no child required more than three practice trials.

The procedure was the same for the hearing children as for the deaf children except that instructions were given verbally. Importantly, no specific spatial terms were used for the hearing children at any time during the study. They received only very general statements ${ }^{7}$ - i.e., the Turkish equivalents of "Watch, I'm putting it here," while placing the winner at the hiding box and "Can you point to the winner in the same place at the finding box?"

3.1.1.3. Neutral trials. After completing the practice trials, children received six neutral test trials. For these trials, only three cards were used per box, as shown in Fig. 4. The winner card was placed at the box in one of the three locations (top, middle, or bottom tier). The child watched as the experimenter placed the three cards at the hiding box, drawing attention to the location of the winner card (because the "winner star" was on the back of the card, once the cards were in the box, there was no visible sign as to which was the winner, so the child had to remember its location). Then, while the children covered their eyes, the experimenter arranged the cards in the finding box, blocking the box with her body and moving all three cards so that hearing children could not use auditory cues to find the winner. At the experimenter's signal, children opened their eyes and tried to point to the winner card in the finding box. If they chose correctly, they were rewarded with clapping. If they chose incorrectly, they were told that they were wrong (either in words or with a head shake), and were shown the correct location of the winner in the finding box. The children were then asked to point to the original location in the hiding box to check whether their initial encoding had been correct--the Memory task, which was administered after each trial.

After each location--top, middle, and bottom--had been tested once, a check trial was administered to ensure that the children still understood the goal of the task. As in the practice trials, four cards were used per box and the winner cards were placed in corresponding locations outside of the boxes (e.g., to the left of their boxes). The child was asked to find the winner, which (as in the practice trials) was a relatively easy task. Three more neutral test trials were then run, after which the child received a second check trial (e.g., with both winners to the right of their boxes). The two easy check trials had a twofold purpose: first, they served to remind the child of the task, and, sec-

\footnotetext{
7 These were the same noninformative phrases used for the control group in Loewenstein and Gentner's (2005) studies.
}

ond, they allowed us to monitor whether the child was following the task instructions.

3.1.1.4. Cross-mapped trials. We next carried out six crossmapped trials using the same procedure. Six patterned cards were used-three different patterns (with distinctive colors and backgrounds) in the hiding box, and the same three patterns in the finding box. As in the neutral task, the winners were always in corresponding locations in their respective boxes. However, in the cross-mapped task, the cards were arranged such that the pattern matches conflicted with the (correct) location matches. For example, if the top-to-bottom pattern order in the hiding box was $A-B-C$, then the order in the finding box would be C-A-B (see Fig. 4). Thus, there was always a competition on the cross-mapped trials between the correct choice (in this case, $A \rightarrow C$ ) and the card with the matching pattern $(A \rightarrow A)$. As in the neutral task, children received practice trials and two check trials with the winner on the sideone after each set of three test trials. As in the neutral task, children shown the correct answer after each trail, and were then administered the Memory task in the initial hiding box.

The dependent measures were the proportions of correct responses produced on the Mapping task and on the Memory task.

\subsection{Results}

The results for the Mapping task (Fig. 4, bottom) were straightforward. Hearing children performed substantially better than the deaf children on both the neutral trials ( $m=0.74, S D=0.89$ for hearing children; $m=0.45$, $S D=0.30$ for the deaf children) and the cross-mapped trials ( $m=0.54, S D=0.34$ for hearing children; $m=0.42$, $S D=0.20$ for the deaf children). A $2 \times 2$ repeated-measures anova over Group (hearing/deaf, between-subjects) and Task (neutral/cross-mapped, within-subjects) revealed a significant effect of Group ( $m=.64, S D=.29$ for hearing children; $m=.42, S D=.25$ for homesigners), $F(1,24)=$ $7.91, p=.01, M S E=.08$. There was no significant effect of Task $^{8}(m=.60$ for neutral trials, $S D=.28 ; m=.48$ for crossmapped trials, $S D=.28), F(1,24)=3.679, p=0.067$, nor was there a significant interaction, $F(1,24)=0.796, p>0.1$.

We also asked how many children in each group scored above chance (i.e., a minimum of $5 / 6$ correct, as dictated by the binomial distribution with $p=.33$ ). In the neutral task, five hearing children and three deaf children scored above chance, a nonsignificant difference, Pearson chisquare $=.72$, NS. In the cross-mapped task, four hearing children and no deaf children scored above chance, Pearson Chi-square $=4.73, p=.048$, one-tailed.

\footnotetext{
8 This contrasts with Loewenstein and Gentner's (2005) finding that children performed worse on the cross-mapped task than on the neutral task. We suspect that this difference arises from the fact that in Loewenstein and Gentner's studies, the two tasks were conducted betweensubjects. In the present study, because of the small number of participants, the tasks were conducted within-subject: all children received the neutral task before the cross-mapped task, allowing for transfer between the tasks.
} 
To determine whether this difference in performance stemmed from a failure to grasp the task on the part of the homesigners, we examined children's performance on the check trials. Because there are four locations in the check trials -3 inside the box and 1 outside the box (the correct location in a check trial)-the child has a .25 probability of choosing the correct location by chance on one check trial, and a .0625 probability of choosing the correct location by chance on both check trials. Both deaf and hearing children performed above chance on the check trials for the neutral and the cross-mapped trials (all $p$ values $<.001$, binomial test).

The results of the Memory task mirrored those of the Mapping task. Children were scored correct on this task if they accurately recalled the location where the experimenter had placed the winner in the finding box. A $2 \times 2$ anova revealed a significant effect of Group $(m=.87$, $S D=0.17$, for hearing children; $m=.64, S D=0.22$, for homesigners), $F(1,24)=12.45, p=.002, M S E=.053$. There was no effect of Task, $F(1,24)=2.787, p>0.1$, and no interaction, $F(1,24)=0.176, p>0.1$. The relatively poor performance of homesigners on the Memory task suggests that they were less able to encode and retain spatial locations than the hearing children. This finding is consistent with the hypothesis that spatial language provides representational resources for encoding spatial relations. The hearing children, whose language provides such resources, were thus better able to encode the initial location than the deaf children.

We next asked how the two groups performed on the Mapping task when they correctly remembered the location in the Memory task. We found that, even when they retained a correct encoding of the initial location, homesigners $(m=.46, S D=0.19)$ performed significantly worse than hearing children $(m=.67, S D=0.19)$ on the Mapping task, $F(1,24)=7.540, p=.011, M S E=.073$. Thus, homesigners were less accurate than hearing children in encoding the initial location, and also less accurate in mapping from one box to another given a correct initial encoding.

\section{Calibration task: Mental Transformation Task (MTT)}

As noted earlier, to avoid contaminating the Spatial Mapping Task, this calibration task was conducted after the Spatial Mapping Task, in a separate session. The participants were the 13 deaf children and 23 hearing children who had participated in the Spatial Mapping Task; we used the MTT scores to match hearing children with deaf children, and retained only the 13 hearing children whose scores most closely matched those of the deaf children. In case of ties (which were rare), age was used as a further selection criterion.

Children were tested in their homes. They were shown two shapes and asked which of four figures the two shapes would make if put together (see Fig. 5). To succeed, children had to mentally slide together (and sometimes rotate) the two shapes. Mean scores on the Mental Transformation Task were $12.31(S D=4.11)$ out of 32 possible correct for the 13 deaf children, and $12.08(S D=3.93)$ for the 13 matched hearing children, $t(24)=.89$.

\section{Discussion}

\subsection{Reasoning about nonlinguistic spatial tasks without language for spatial relations}

Our study has two key findings. First, deaf children who had not been exposed to a conventional language model rarely produced homesign gestures that conveyed spatial relations between two objects. This result is all the more striking in view of the fact that the manual modality seems to lend itself readily to capturing these relations (see, for example, Emmorey, 2002a). Second, homesigners performed poorly on a Spatial Mapping Task compared to cognitively-matched hearing children. These findings are consistent with the claim that learning a language that has linguistic devices for encoding spatial relations confers cognitive benefits when reasoning about such relations.

Although the nature of our data does not allow us to make a definitive causal claim, we suggest that the home-

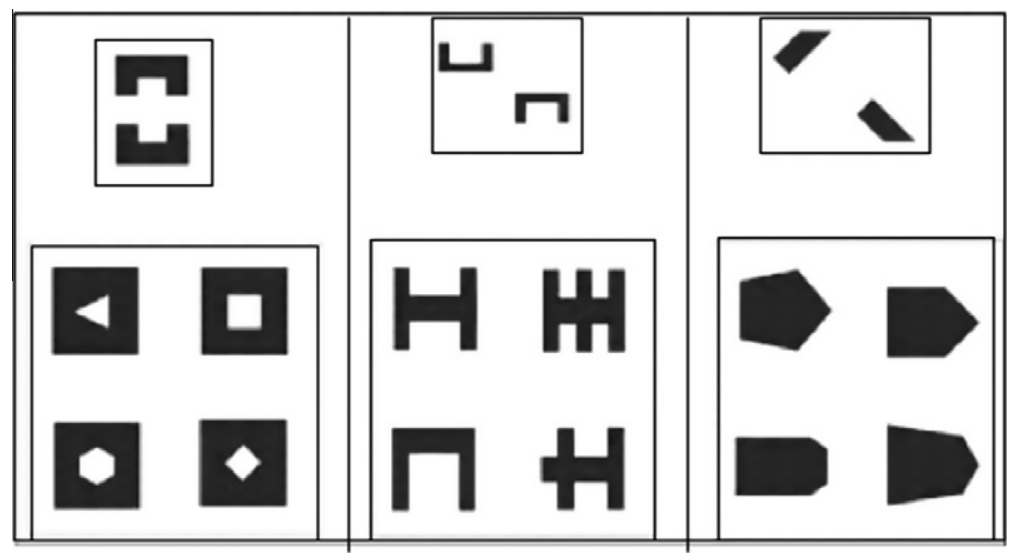

Fig. 5. Apparatus and results for the Spatial Mapping Task. Top displays the apparatus for the neutral (left) and cross-mapped (right) tasks. Bottom displays proportion correct for deaf and hearing children on the two versions of the task. 
signers' lack of gestures portraying the spatial relation between two objects is related to their poor performance on the spatial mapping and memory tasks. The hearing children in our study had been exposed to and learned the systematic semantic spatial distinctions in their language and could fluently access terms like top/on (ust), middle (orta), and bottom/under (alt), and the Childes analysis further bears out that the hearing children were likely to have had a rich vocabulary of spatial terms. In contrast, the deaf children had no codified means to facilitate access to these spatial categories. The deaf children could, of course, have invented an ad hoc set of gestures or combinations of gestures on the spot to capture the spatial categories relevant to the task--their basic perception is intact. But this is a challenge that hearing children do not face--they can simply draw on the spatial categories of the language that they have already learned. Further, if the deaf children were to develop gestures for spatial categories on the spot, any such newly developed gestures would be unlikely to be as stable and robust as a well-learned spatial system.

In our view, the fact that the children had not, up until this point, invented gestures that portrayed spatial relations of this sort suggests that these notions may not be easy for children to extract and encode on their own, even in the manual modality. Along these lines, the sign language acquisition literature shows that learning to encode spatial relations in adult-like ways is a relatively late development, even in children exposed to sign language from birth by their deaf parents (in part because learning and perfecting classifier predicates is a relatively late developmental step, Brentari, Coppola, Jung, \& GoldinMeadow, 2013; Schick, 1990; Supalla, 1982). Thus, it is not surprising that young homesigners do not invent these constructions without a target model.

Homesigners were also less accurate than hearing children at recalling the winner's location in the initial hiding box, suggesting that they were less able to encode the precise details of the spatial scene than were hearing children. The homesigners' memory difficulties dovetail with Loewenstein and Gentner's (2005) findings. In one task, 3year-old children were asked to remember the location of a toy in a single three-tiered box (like those used here) for a brief interval (about $30 \mathrm{~s}$ ). Children were better able to remember the toy's location if the box had previously been described using spatial language (top, middle, bottom) than if it had been described using non-spatial language (see also Dessalegn \& Landau, 2008). Our results add to this finding and suggest that learning a language that has linguistic devices for encoding spatial relations confers cognitive benefits not only when reasoning about the relations, but also when encoding and recalling them.

Our findings are consistent with previous research on hearing children. Young American hearing children can carry out a challenging spatial mapping at 31/2-4 years if reminded of relevant spatial terms. By $5 \frac{1}{2}$ years, American hearing children no longer need the support of overt language to carry out the mapping (Loewenstein \& Gentner, 2005). The Turkish hearing children in our study, like older American children, did not need to be reminded of the relevant spatial terms during the task but seemed to recruit them-or the semantic system conveyed by them-on their own. They performed well on the Spatial Mapping Task even though the experimenter never mentioned the spatial terms.

\subsection{Limitations}

A degree of caution is warranted in interpreting our findings. We have emphasized that the homsigners' lack of access to conventional spatial language left them at a disadvantage relative to the hearing children in encoding the relevant spatial relations. But the lack of language also meant that their experiences differed substantially from those of the hearing children in many respects. Although the deaf children were well-integrated into their families and appeared bright and engaged, they were obviously limited in their access to the learning opportunities that a conventional language affords. Their limited access raises the concern that the differences we found between groups in the Spatial Mapping Task stemmed from some extraneous difference between the groups, such as failure to understand the task on the part of the homesigners. Although we cannot entirely remove this concern, we attempted to minimize extraneous differences between the two groups in several ways.

First, the nature of the Spatial Mapping Task is such that all of the information required to solve the task is (at least in principle) perceptually available, and the correct answer was shown on every trial. Second, we gave the deaf children a much more extensive familiarization session than we gave the hearing children. They received $10-15 \mathrm{~min}$ of familiarization and practice with the gestures and concepts needed to succeed on the task-even those that we assumed would be familiar to the children--compared to 2-3 min for the hearing children. Third, we equated the deaf and hearing children on the Mental Transformation Task; in fact, our matching procedure resulted in an age advantage for the deaf children (mean age of 5 years, 6 months) over the hearing children (mean age of 4 years, 10 months). Finally, we included check trials to assess whether children understood the task, and found that both deaf and hearing children performed above chance on these trials. Thus, although we cannot rule out the possibility that other factors entered into our findings, we suggest that the results of our two main tasks are indeed meaningful: Children who lack spatial language are disadvantaged on a spatial reasoning task relative to those who possess such language.

Moreover, our results cohere with recent work showing a strong relation between spatial language and spatial cognition in an emerging sign language, Nicaraguan Sign Language (NSL). As discussed earlier, as this new language has passed from the 1 st cohort of users to the 2 nd cohort, it has become linguistically richer and more expressive (Senghas et al., 2004). Pyers et al. (2010) first documented greater linguistic specificity and consistency in marking spatial relations in signers in the 2 nd cohort than in the $1 \mathrm{st}$. They then went on to show that deaf adults who had learned the second iteration of NSL performed better on a nonlinguistic spatial task than did deaf adults who had acquired the first iteration of the language. As in our study, the nature of the spatial constructions that the signers had mastered in their 
language predicted their performance on nonlinguistic spatial tasks. The effect in our study is perhaps more dramatic in that it involves presence vs. absence of spatial language, rather than more vs. less consistent use of spatial language, as in the NSL case. In addition, the fact that spatial referring symbols and constructions did not emerge until the second iteration of NSL is consistent with our finding that homesigners-who are essentially developing their own "first iteration" symbolic systems-lack such terms.

\subsection{Whence prepositions (and other terms for static spatial relations)?}

This last point leads to an intriguing conjecture: Perhaps despite their seeming obviousness to adult speakers of a language, terms for static spatial relational meanings are particularly hard to invent and/or learn, compared to terms referring to objects and actions and even compared to terms referring to dynamic spatial relations (i.e., directional relations such as to and from, which the homesigners did routinely encode in their gestures). At first glance, this hypothesis might seem surprising. After all, static spatial relations remain visible for extended periods, unlike actions, which are often ephemeral.

However, several pieces of evidence support the speculation. First, there is Hyde et al.'s (2011) finding that a 13year-old deaf child who had received essentially no language input was able to convey the number of objects in a scene but not the spatial relation between two objects. A second line of evidence is the extraordinary length of time (in view of their high input frequency) required to acquire the meanings of terms that refer to static spatial relations (e.g., prepositions), as documented by Roger Brown (1973) for English-speaking children (see also Gentner, 1982). A third line of evidence comes from linguistic typology (e.g., Heine, 1997; Hopper \& Traugott, 2003) suggesting that adpositions (both prepositions and postpositions) often evolve over long periods through grammaticalization ${ }^{9}$ processes that operate on nouns and verbs. For example, Heine (1997) describes the gradual evolution of the Swahili term mbele. It began as the body part term "breast;" it was then extended to become a more general part term meaning "frontside or front part," then further extended to become a purely locational term meaning "the front" or "in front of," and finally extended (still more abstractly) to become a temporal marker meaning "before." A fourth line of support for the idea that spatial language may not be early to emerge is that there are no reports of spatial language in newly emerging sign languages (e.g., Al-Sayyid Bedouin Sign Language, Meir et al., 2010) or village sign languages (e.g., Zeshan, 2010). As research on these young sign languages (and on adult homesigners) advances, we may have the opportunity to observe the emergence of spatial

\footnotetext{
9 As defined by Lehmann (1982), "Grammaticalization is a process leading from lexemes to grammatical formatives. A number of semantic, syntactic and phonological processes interact in the grammaticalization of morphemes and of whole constructions. A sign is grammaticalized to the extent that it is devoid of concrete lexical meaning and takes part in obligatory grammatical rules".
}

language. An intriguing conjecture, based on our findings and the above discussion, is that directional spatial termsthose conveyed by adpositions such as to, at and frommay emerge earlier than static spatial relations such as in, on, in and under.

\subsection{Summary}

Our findings are consistent with a large body of research on the close relation between language and cognition. But our findings take the phenomenon one important step further. We show that deaf children who have not learned or invented constructions for conveying spatial relations, and thus have no systematic linguistic expressions to recruit, display severe limitations in spatial cognition, even at 5 years of age. The lack of spatial language appears to leave children at a serious disadvantage in memory for, and mapping of, spatial locations, relative to children who have acquired language with devices that convey spatial relations. Our findings thus add to the growing literature that language provides cognitive tools for thinking about space.

\section{Acknowledgements}

Supported by NSF SLC Grant SBE-0541957, Spatial Intelligence and Learning Center (SILC), and R01DC00491 to SGM, European Research Council Starting Grant (ERC) to $\mathrm{AO}$, and the Max Planck Institute for Psycholinguistics. We thank Koc University for the use of facilities, and the Humboldt Foundation and the Hanse-Wissenschaftskolleg for support to DG during preparation of this paper. We also thank B. Sancar, R. Furman, K. Braun, and G. Honke for data collection and analysis.

\section{References}

Arık, E., \& Wilbur, R. (January, 2008). Locatives, existentials, and possessives in Turkish Sign Language (TID). In Poster presented at the $82 \mathrm{nd}$ annual meeting of the LSA, Chicago, IL.

Bowerman, M. (1996). Learning how to structure space for language: A crosslinguistic perspective. In P. Bloom, M. A. Peterson, L. Nadel, \& M. F. Garrett (Eds.), Language and space (pp. 385-436). Cambridge, MA: MIT Press.

Brentari, D., Coppola, M., Jung, A., \& Goldin-Meadow, S. (2013). Acquiring word class distinctions in american sign language: Evidence from handshape. Language Learning and Development, 9(2), 1-21.

Brown, R. (1973). A first language: The early stages. Cambridge, MA: Harvard University Press.

Dessalegn, B., \& Landau, B. (2008). More than meets the eye: The role of language in binding and maintaining feature conjunctions. Psychological Science, 19(2), 189.

Emmorey, K. (2002a). Language, cognition, and the brain: Insights from sign language research. Lawrence Erlbaum Associates.

Emmorey, K. (2002b). The effects of modality on spatial language: How signers and speakers talk about space. In R. P. Meier, D. G. Quinto, \& K. A. Cormier (Eds.), Modality and structure in signed and spoken languages (pp. 405-421).

Emmorey, K. (1996). The confluence of space and language in signed languages. In P. Bloom, M. A. Peterson, L. Nadel, \& M. F. Garrett (Eds.), Language and space (pp. 171-209). Cambridge, MA: MIT Press.

Engberg-Pedersen, E. (1993). Space in Danish sign language. Hamburg: Signum-Verl.

Frank, M. C., Everett, D. L., Fedorenko, E., \& Gibson, E. (2008). Number as a cognitive technology: Evidence from Pirahã language and cognition. Cognition, 108(3), 819-824.

Gentner, D. (2010). Bootstrapping the mind: Analogical processes and symbol systems. Cognitive Science. 
Gentner, D., \& Christie, S. (2010). Mutual bootstrapping between language and analogical processing. Language and Cognition, 2(2), 261-283.

Gentner, D. (2003). Why we're so smart. In D. Gentner \& S. GoldinMeadow (Eds.), Language in mind: Advances in the study of language and thought (pp. 195-235). Cambridge, MA: MIT Press.

Gentner, D., \& Goldin-Meadow, S. (2003). Whither Whorf. In D. Gentner \& S. Goldin-Meadow (Eds.), Language in mind advances in the study of language and thought (pp. 3-14). Cambridge, MA: MIT Press.

Gentner, D. (1982). Why nouns are learned before verbs: Linguistic relativity versus natural partitioning. In S. Kuczaj (Ed.), Language development. Language, thought and culture (Vol. 2, pp. 301-334). Hillsdale, NJ: Erlbaum.

Gleitman, L., \& Papafragou, A. (2005). Language and thought. In K. J. Holyoak \& R. G. Morrison (Eds.), Cambridge handbook of thinking and reasoning (pp. 117-142). Cambridge: Cambridge University Press.

Goldin-Meadow, S. (2003). The resilience of language: What gesture creation in deaf children can tell us about how all children learn language. NY: Taylor \& Francis (Psychology Press).

Goldin-Meadow, S., \& Mylander, C. (1984). Gestural communication in deaf children: The effects and noneffects of parental input on early language development. Monographs of the Society for Research in Child Development, 1-151.

Goldin-Meadow, S., So, W. C., Özyürek, A., \& Mylander, C. (2008). The natural order of events: How speakers of different languages represent events nonverbally. Proceedings of the National Academy of Sciences, 105(27), 9163.

Gumperz, J. J., \& Levinson, S. C. (1996). Rethinking linguistic relativity. Cambridge, UK: Cambridge University Press.

Haun, D. B. M., Rapold, C. J., Call, J., Janzen, G., \& Levinson, S. C. (2006) Cognitive cladistics and cultural override in Hominid spatial cognition. Proceedings of the National Academy of Sciences, 103 17568-17573.

Heine, B. (1997). Cognitive foundations of grammar. New York: Oxford University Press.

Hermer-Vasquez, L., Moffet, A., \& Munkholm, P. (2001). Language, space, and the development of cognitive flexibility in humans: The case of two spatial memory tasks. Cognition, 79, 263-299.

Hermer-Vasquez, L., Spelke, E. S., \& Katsnelson, A. S. (1999). Sources of flexibility in human cognition: Dual-task studies of space and language. Cognitive Psychology, 39, 3-36.

Hopper, P. J., \& Traugott, E. C. (2003). Grammaticalization (2nd ed.). Cambridge: Cambridge University Press

Hyde, D. C., Winkler-Rhoades, N., Lee, S. A., Izard, V., Shapiro, K. A., \& Spelke, E. S. (2011). Spatial and numerical abilities without a complete natural language. Neuropsychologia, 49(5), 924-936.

Lehmann, C. (1982). Thoughts on grammaticalization. A programmatic sketch. Arbeiten des Kölner Universalien-Projekts (Vol. I, Nr. 48)

Levine, S. C., Huttenlocher, J., Taylor, A., \& Langrock, A. (1999). Early sex differences in spatial skill. Developmental Psychology, 35(4), 940-948.

Levinson, S. C. (2003). Space in language and cognition. Cambridge: Cambridge University Press.

Li, P., \& Gleitman, L. (2002). Turning the tables: Language and spatial reasoning. Cognition, 83(3), 265-294.

Loewenstein, J., \& Gentner, D. (2005). Relational language and the development of relational mapping. Cognitive Psychology, 50(4), 315-353.

MacWhinney, B. (2000). The CHILDES project: Tools for analyzing talk (3rd ed.). Mahwah, NJ: Lawrence Erlbaum Associates.

Majid, A., Bowerman, M., Kita, S., Haun, D. B., \& Levinson, S. C. (2004). Can language restructure cognition? The case for space. Trends in Cognitive Sciences, 8(3), 108-114.
Malt, B., \& Wolff, P. (2010). Words and the mind. Oxford, UK: Oxford University Press.

Meir, I., Sandler, W., Padden, C., \& Aronoff, M. (2010). Emerging sign languages. In M. Marschark \& P. Spencer (Eds.). Oxford handbook of deaf studies, language, and education (Vol. 2, pp. 267-280). Oxford: Oxford University Press.

Miller, C. (1994). Simultaneous constructions in Quebec Sign Language. In M. Brennan \& G. Turner (Eds.), Word-order issues in sign language. Working papers (pp. 89-112). Durham, UK: International Sign Linguistics Association.

Morgan, G., \& Woll, B. (2007). Understanding sign language classifiers through a polycomponential approach. Lingua, 117(7), 1159-1168.

Özyürek, A., Zwitserlood, I., \& Perniss (2010). Locative expressions in sign languages: A view from Turkish Sign Language (TID). Linguistics, 48(5), 1111-1145.

Perniss, P., Vermeerbergen, M., Leeson, L., \& Crasborn, O. (2007). Locative functions of simultaneous perspective constructions in German Sign Language narratives. In Simultaneity in Signed Languages: Form and function (pp. 27-54). Amsterdam: John Benjamins.

Pruden, S. M., Levine, S. C., \& Huttenlocher, J. (2011). Children's spatial thinking: Does talk about the spatial world matter? Developmental Science, 14(6), 1417-1430.

Pyers, J. E., Shusterman, A., Senghas, A., Spelke, E. S., \& Emmorey, K. (2010). Evidence from an emerging sign language reveals that language supports spatial cognition. Proceedings of the National Academy of Sciences, 107(27), 12116-12120.

Schick, B. (1990). The effects of morphosyntactic structures on the acquisition of classifier predicates in ASL. In C. Lucas (Ed.), Sign Language research: Theoretical Issues (pp. 358-371). DC: University of Gallaudet Press.

Senghas, A., \& Coppola, M. (2001). Children creating language: How Nicaraguan sign language acquired a spatial grammar. Psychological Science, 12(4), 323-328.

Senghas, A., Kita, S., \& Özyürek, A. (2004). Children creating core properties of language: Evidence from an emerging sign language in Nicaragua. Science, 305, 1779-1782.

Simms, N., \& Gentner, D. (2008). Spatial language and landmark use: Can 3-, 4-, and 5-year-olds find the middle? In B. C. Love, K. McRae, \& V. M. Sloutsky (Eds.), Proceedings of the 30th annual conference of the cognitive science society (pp. 191-196). Austin, TX: Cognitive Science Society.

Supalla, T. R. (1982). Structure and acquisition of verbs of motion and location in American Sign Language. Univ. Microfilms International.

Supalla, T. (2003). Revisiting visual analogy in ASL classifier predicates. In K. Emmorey (Ed.), Perspectives on classifier constructions in sign languages (pp. 249-258). Mahwah, NJ: Lawrence Erlbaum Associates.

Talmy, L. (1975). Syntax and semantics of motion. In J. Kimball (Ed.). Syntax and semantics (Vol. 4, pp. 181-238). New York: Academic Press.

Talmy, L. (1983). How language structures space. In H. Pick \& L. P. Acredolo (Eds.), Spatial orientation: Theory, research, and application (pp. 225-282). New York: Plenum.

Tang, G., Sze, F., \& Lam, S. (2007). Acquisition of simultaneous constructions by deaf children of Hong Kong Sign Language. In M. Vermeerbergen, L. Leeson, \& O. Crasborn (Eds.), Simultaneity in signed languages: Form and function (pp. 283-316).

Zeshan, U. (2010). Village sign languages. In G. Mathur \& D. J. Napoli (Eds.), Deaf around the world: The impact of language (pp. 221-230). Oxford, UK: Oxford University Press. 